\title{
JAMES (2014) DE CLAIRE OAKLEY. EDWARD JENNER Y LA VACUNA CONTRA LA VIRUELA
}

\author{
James (2014) by Claire Oakley. Edward Jenner and the Smallpox Vaccine
}

\author{
Miguel ABAD VILA \\ Centro de Saúde Novoa Santos. Ourense (España). \\ Correo electrónico: mabadvila@gmail.com
}

Fecha de recepción: 10 de agosto de 2020

Fecha de aceptación: 14 de agosto de 2020

Fecha de publicación: 29 de enero de 2021

\begin{abstract}
Resumen
Hasta la actualidad, la viruela es la única enfermedad infecciosa humana que la vacunación sistemática ha conseguido erradicar. El 14 de mayo de 1796, el médico rural, naturalista y poeta británico Edward Jenner (Berkeley, Inglaterra, 17 de mayo de 1749 - Berkeley, Inglaterra, 27 de enero de 1823) inoculaba a James Phipps, de 8 años de edad, el material purulento procedente de las ampollas de las manos de la lechera Sarah Nemes. Esta campesina estaba infectada de viruela bovina, una enfermedad similar a la viruela humana pero mucho menos agresiva, y que protegía a estas personas de los terribles efectos de la viruela, entonces capaz de contagiar al $60 \%$ de la población y causar la mortalidad del $20 \%$. De esta manera, el pequeño James quedó inmunizado contra esta enfermedad. Desde entonces, y hasta el fallecimiento de Edaward Jenner, James Phipps trabajaría a su servicio en sus tierras de Berkeley, en Gloucestershire (Reino Unido). James (2014) de Claire Oakley, es un corto de 15 minutos que recrea magistralmente cómo se gestó la vacunación del doctor Jenner contra la viruela.

Palabras clave: viruela; vacunación; pandemia; corto.
\end{abstract}

\section{Abstract}

To the present, smallpox is the only human infectious disease that routine vaccination has eradicated successfully. On May 14, 1796, British rural physician, naturalist and poet Edward Jenner 
(Berkeley, England, May 17, 1749 - Berkeley, England, January 27, 1823) inoculated 8-years-old boy James Phipps with the purulent material obtained from the blisters that milkmaid Sarah Neme had in her hands. The peasant was infected with cowpox, a disease similar to smallpox, but much less virulent, and what protection for these people from the terrible effects of smallpox, capable of infecting $60 \%$ of the population and causing mortality $20 \%$. In this way, little James was immunized against this virulent disease. Since then, and until Edward Jenner's dead, James Phipps worked in his service on his Berkeley lands in Gloucestershire, United Kingdom. James (2014) by Claire Oakley, is a 15-minute short that masterfully recreates how doctor Jenner's vaccination against smallpox takes place.

Keywords: smallpox; vaccination; pandemic; short.

"Los que estaban celosos de su fama se volvieron más audaces; sus amistades se volvieron tibias; sus enemigos más unidos y estruendosos; las demandas sobre su tiempo y atención se incrementaron; sus recursos privados disminuyeron; y no pudo dedicarse a su ejercicio profesional como médico" ${ }^{1}$.

John Baron. The Life of Edward Jenner, 1838.

\section{FICHA TÉCNICA}

Título: James.

Título Original: James.

País: United Kingdom.

Año: 2014.

Director: Claire Oakley.

Música: Isobel Waller-Bridge.

Fotografía: Taina Galis.

Guion: Felix Levinson.

Intérpretes: Jack Hollington (James), Morgan Watkins (el padre de James), Anna Koval (la madre de James), Fredbie Schepens (el bebé), Robert Cavanah (Dr. Jenner), Cordelia Levinson (criada de Jenner), Natalie Powers (Sarah Nelmes), Tara Holland (niña enferma de viruela), Susy Copus (madre de la niña enferma de viruela), Stephen Scheiber (Henry Hicks), Andrew Figgins (campesino), Roger Harris (campesino), Yvonne Hoskins (campesina), Toby Meredith (campesino), Anna James (campesina)
Color: color.

Duración: 15 minutos.

Género: corto, drama, familia.

Idioma original: inglés.

Productores: Terhi Kylliainen, Fleix Levinson.

Sinopsis: En 1876, en Gloucestershire, Inglaterra, el doctor Edward Jenner le ofrece trabajo a un humilde jornalero. A cambio, debe permitir que su hijo pueda ser utilizado en un arriesgado experimento médico. Basado en la vida de James Phipps, el niño de 8 años en el que Jenner probó la primera vacuna contra la viruela en el mundo.

Enlaces: https://www.imdb.com/title/tt3678992

$$
\begin{aligned}
\text { /?ref_=ttpl_pl_tt } & \\
& \text { Tráiler original }
\end{aligned}
$$

\section{INTRODUCCIÓN}

En el momento más álgido de la pandemia provocada por el coronavirus SARS-Cov-2, con 20 millones de casos y más de 736000 fallecidos en todo el mundo ${ }^{2}$, mientras varios equipos científicos internacionales intentan desarrollar una vacuna eficaz que pueda contrarrestar el avance de la COVID-19 (la enfermedad contagiosa causada por este coronavirus), resulta emocionante contemplar un corto cinematográfico de apenas un cuarto de hora que nos traslada precisamente al momento en el que se puso en marcha la vacunación contra la viruela, para algunos expertos la enfermedad más letal de la historia de la Humanidad. Se estima que tan solo durante el pasado 
siglo XX, la viruela fue responsable de unos 300 millones de fallecimientos en el mundo.

Existen cuatro formas de la denominada viruela mayor, la más grave, que causa la mortalidad del $30 \%$ de los infectados: la común y más frecuente, observada en el $90 \%$ de los casos, la modificada, más leve y en personas que se habrían vacunado previamente, la lisa y la hemorrágica, ambas más raras, pero mucho más letales.

El origen de la viruela, causada por el virus variola, es desconocido ${ }^{3}$, si bien se cree que pudo surgir en asentamientos humanos de hace más de 10000 años $^{4}$. Evidencias de esta enfermedad han sido encontradas en algunas momias egipcias del siglo III a. C. ${ }^{5}$. Las primeras descripciones de una enfermedad parecida a la viruela se remontan a China, en el siglo IV d. C., mientras que las primeras reseñas de la viruela son del siglo VII d. C., en la India.

El Doctor Abraham L. Baron nos cuenta una terrible historia. En el 64 d. C., el año del Gran Incendio que arrasó gran parte de la ciudad de Roma durante el reinado de Nerón, sus victoriosas legiones invadieron Siria, arrasando con todo aquello que no pudieron disipar o llevarse. Inmersos en una tremenda orgía de pillaje y vandalismo, la soldadesca romana alcanzó el templo de Apolo en la procura de oro y joyas. Allí descubrieron un recóndito lugar sagrado, donde se custodiaba un viejo cofre protegido por los sagrados hechizos de los antiguos nigromantes caldeos. Cuando aquellos osados forzaron el arca, una pestilencia letal fue liberada. De regreso a casa, portaban consigo una espantosa epidemia de viruela que azotó la capital del imperio durante 15 años $^{6}$.

En los los siglos XI y XII, se responsabilizó a los cruzados que retornaban a casa de la diseminación de la viruela por toda Europa. Durante centenares de años, la viruela mortificó al Viejo Mundo, pero sus efectos resultaron especialmente devastadores para los nativos del Nuevo
Mundo, tras el descubrimiento y la conquista de América, carentes por completo de las defensas inmunitarias específicas contra esta enfermedad. En 1520 diezmó a los mexicas durante el sitio de la capital del imperio azteca mundo ${ }^{7}$, y entre los incas, aliada con otras patologías infecciosas como el sarampión y la gripe, ocasionó un desastre demográfico de tales dimensiones que de 18 millones de habitantes autóctonos existentes a la llegada de los conquistadores españoles, se pasó a los 1.5 millones en el siglo XVIII mundo ${ }^{8}$.

En 1763, Lord Jeffrey Amherts, comandante en jefe de las fuerzas británicas en América del Norte, ordenó el reparto de mantas infectadas de viruela entre las tribus delaware hostiles que asediaban Fort Pitt, en la confluencia de los ríos Monongahela y Allegheny, en Pensilvania'. Una acción pionera de la guerra biológica.

\section{LA INOCULACIÓN DE LA VIRUELA}

Esta práctica se inició en Inglaterra en 1721, intentando transmitir la infección mediante la introducción de material de una pústula de viruela en una pequeña incisión practicada en la piel del prójimo sano, entre los dedos pulgar e índice de una de sus manos. Los inoculados podían así contraer la viruela, si bien algunos desafortunadamente fallecían como consecuencia de esta intervención. Pero lo más habitual era que desarrollaran una sintomatología leve, con fiebre y pústulas escasas. A cambio, la inmunidad adquirida resultaba equivalente a la provocada por la infección natural.

La inoculación se extendió por Inglaterra en la década de 1740 , siendo especialmente generalizada a partir de 1770 , en las comunidades rurales y las pequeñas ciudades. Y si bien fue introducida en Londres en 1721 por Lady Mary Wortley Montagu, esposa del embajador británico en Constantinopla, para proteger a sus hijos de una enfermedad que ella misma llegó a padecer, lo cierto es que esta operación era popular y habitual en Turquía, Arabia, norte de África, 
Persia y la India, importada de China, donde antiguos textos del siglo XI ya la describían con detalle ${ }^{10}$.

\section{EL CORTOMETRAJE}

Si bien la inoculación de la viruela era una práctica usual en la Inglaterra rural, no cabe duda de que el hambre y la miseria, disfrazadas en la pantalla bajo la apariencia de la fe ciega en la profesionalidad del galeno, empujaron a John Phipps (Morgan Watkins) a aceptar que su hijo James (Jack Hollington) participara en el experimento del doctor Jenner (Robert Cavanah). Después de haber perdido a su primogénito Thomas por culpa de esta enfermedad, cuyo espanto revive el pequeño cuando contempla a un grupo de campesinos portando en parihuela a una niña vecina (Tara Holland) plagada de pústulas, el padre se resigna ante el riesgo de una nueva tragedia familiar.

Mientras la enfermedad campa a sus anchas, la vida bulle en la campiña inglesa: las plantas crecen en el jardín, las abejas liban sus flores, las vacas en rebaños pacen mansamente en los prados, en una metáfora de cuál será la procedencia de la futura curación de la viruela.

El doctor Jenner era un médico rural, pero también un ilustrado naturalista, como demuestran los objetos que colecciona en su despacho: cráneos de animales, frascos con embriones, colecciones de insectos y de conchas. A su servicio tiene una criada (Cordelia Levinson) con el rostro marcado por las cicatrices de la viruela.

El primer encuentro entre el médico y el niño tuvo lugar en el jardín. Jenner le descubre el nombre de la supuesta mala hierba que James acaba de arrancar, Achillea millefolium o la ortiga del diablo. En este aspecto, existe una confusión pues la Achillea millefolium es el perejil bravío o flor da la pluma, entre otras denominaciones, una planta herbácea que florece en forma de corimbos, y a pesar de cierta toxicidad, poseedora de propiedades medicinales: antiinflamatorias, cicatrizantes, hemostáticas, antisépticas, colagogas, antiespasmódicas y tonificantes. El propio Jenner recomienda al chico infusiones de Achillea para tratar la fiebre post-vacunal.

En 1788, una epidemia de viruela se había extendido por Gloucestershire, siendo Jenner uno de los médicos encargados de enfrentarse al brote. Observó entonces que las personas previamente infectadas por la viruela vacuna, una enfermedad mucho más leve y localizada, se encontraban inmunizadas frente a los estragos de la viruela humana. Es más, mientras familias completas sucumbieron a esta enfermedad, las víctimas de la viruela vacuna se mantuvieron sanas.

Empleando un método semejante a la inoculación, Jenner depositó en este caso material procedente de una pústula de las manos de la lechera Sarah Nelmes (Natalie Powers) mediante un pequeño corte realizado con un bisturí en la cara anterior del antebrazo del pequeño James.

Después de un cuadro febril repleto de extraños sueños, en los que el niño revive las imágenes de la descomposición del cadáver de un zorro que solía visitarlo en vida, James fue revisado nuevamente por el doctor Jenner, esta vez en presencia de su íntimo amigo Henry Hicks (Stephen Schreiber), ratificando la inmunidad del muchacho frente a la viruela.

Tras la conclusión de los experimentos de Jenner, Hicks fue el primero en someter a toda su extensa prole a la nueva práctica vacunal, lo que sirvió de acicate para la nobleza local. Su ejemplo fue seguido por la condesa de Berkeley y por Lady Frances Moreton, más tarde Duquesa de Ducie ${ }^{11}$.

Jenner demostró su descubrimiento con otras 23 vacunaciones adicionales. Finalmente, su procedimiento fue aceptado por el gobierno británico en 1840, que prohibió la inoculación de la viruela para sustituirla por la vacunación gratuita, según el modelo de Jenner.

La relación de amistad floreció entre el médico y su antiguo paciente, y se fue fortaleciendo con 


\section{JAMES (2014) DE CLAIRE OAKLEY. EDWARD JENNER Y LA VACUNA CONTRA LA VIRUELA MIGUEL ABAD VILA}

el paso de los años. Así, el doctor Jenner le proporcionó al joven James y a su familia el contrato de alquiler gratuito de una cabaña en Berkeley, que posteriormente fue destinada al Museo Edward Jenner, entre 1968 y 1982.

El 3 de febrero de 1823, James Phipps se encontraba entre los presentes en el funeral de su benefactor, fallecido a causa de un ictus ${ }^{12}$. Tres décadas más tarde, el propio James sería enterrado en la iglesia de Santa María de Berkeley, donde había sido bautizado, y donde también reposan los restos del doctor Edward Jenner.

En la banda sonora de este cortometraje, a cargo de Isobel Waller-Bridge, destacamos la versión de la canción tradicional inglesa Scarborough Fair, de autor desconocido. Popularizada por Simon y Garfunkel en El graduado (1967) de Mike Nichols, y que menciona una mezcla de plantas (perejil, salvia, romero y tomillo), ingredientes de una supuesta pócima de amor, muy famosa durante la Edad Media.

\section{REFERENCIAS}

1. Baron J. The Life of Edward Jenner. Londres: Henry Colburn Publisher;1838.

2. RTVE.es. Coronavirus: Mapa Mundial. RTVE. 11 de agosto de 2020 .
3. McKeown T. Los orígenes de las enfermedades humanas. Barcelona. Editorial Crítica. 1990.

4. Barquet N, Domingo P. Smallpox: the triumph over the most terrible of ministers of death. Ann Intern Med, 1997, 127 (8): 635-42.

5. Centers for Disease Control and Prevention. History of Smallpox. 2016.

6. Baron A.L. Man Againts Germs. Londres: Scientific Book Club Edition. 1958.

7. García Sánchez F. Celis Salazar H. Carboney Mora C. Viruela en la república Mexicana. Salud Pública de México, [S.I.], v. 34, n. 5, p. 577-587, sep. 1992. ISSN 1606-7916. [Consultado el 11 de agosto de 2020].

8. García Cáceres Uriel. La implantación de la viruela en los Andes, la historia de un holocausto. Rev Perú Med Exp Salud Pública. 2003; 20(1): 41-50.

9. Mann B.A. The Tainted Gift: The Disease Method of Frontier Expansion. Native America: Yesterday and Today, Bruce S. Johansen, Series Editor. Santa Barbara, California: Praeger ABC-CLIO. 1947.

10. McNeill W.H. Plagas y pueblos. Madrid: Siglo XXI de España Editores. 1978.

11. Mills Stephen. Dr Jenner and Henry Hicks. History Archieve. Eastington Community News. [Consultado el 11 de agosto de 2020]

12. Morgan AJ, Parker S. Translational mini-review series on vaccines: The Edward Jenner Museum and the history of vaccination. Clin Exp Inmunol. 2007; 147 (3): $389-94$

Miguel Abad Vila. Licenciado en Medicina por la Universidad de Santiago
de Compostela. Doctor en Medicina por la Universidad de Santiago de
Compostela. Diplomado en Salud Pública. Máster en Gestión Sanitaria por
la Universidad de Vigo. Máster en Derecho Sanitario por la Universidad
de Castilla - La Mancha. Médico de Familia en el Centro de Saúde "Novoa
Santos", Servizo Galego e Saúde, Ourense. Colaborador habitual de "La
Región" (Ourense), "Atlántico Diario" (Vigo) y "Onda Cero" (Ourense).
Autor de los blogs "Cartas de Aloysius" y "MEDYCINE".

